NASA/TM-1999-209637

\title{
Testing of the Engineering Model Electrical Power Control Unit for the Fluids and Combustion Facility
}

Greg L. Kimnach and Ramon C. Lebron

Glenn Research Center, Cleveland, Ohio

David A. Fox

Hamilton Sundstrand Aerospace, Rockford, Illinois 
Since its founding, NASA has been dedicated to the advancement of aeronautics and space science. The NASA Scientific and Technical Information (STI) Program Office plays a key part in helping NASA maintain this important role.

The NASA STI Program Office is operated by Langley Research Center, the Lead Center for NASA's scientific and technical information. The NASA STI Program Office provides access to the NASA STI Database, the largest collection of aeronautical and space science STI in the world. The Program Office is also NASA's institutional mechanism for disseminating the results of its research and development activities. These results are published by NASA in the NASA STI Report Series, which includes the following report types:

- TECHNICAL PUBLICATION. Reports of completed research or a major significant phase of research that present the results of NASA programs and include extensive data or theoretical analysis. Includes compilations of significant scientific and technical data and information deemed to be of continuing reference value. NASA's counterpart of peerreviewed formal professional papers but has less stringent limitations on manuscript length and extent of graphic presentations.

- TECHNICAL MEMORANDUM. Scientific and technical findings that are preliminary or of specialized interest, e.g., quick release reports, working papers, and bibliographies that contain minimal annotation. Does not contain extensive analysis.

- CONTRACTOR REPORT. Scientific and technical findings by NASA-sponsored contractors and grantees.
- CONFERENCE PUBLICATION. Collected papers from scientific and technical conferences, symposia, seminars, or other meetings sponsored or cosponsored by NASA.

- SPECIAL PUBLICATION. Scientific, technical, or historical information from NASA programs, projects, and missions, often concerned with subjects having substantial public interest.

- TECHNICAL TRANSLATION. Englishlanguage translations of foreign scientific and technical material pertinent to NASA's mission.

Specialized services that complement the STI Program Office's diverse offerings include creating custom thesauri, building customized data bases, organizing and publishing research results ... even providing videos.

For more information about the NASA STI Program Office, see the following:

- Access the NASA STI Program Home Page at http://www.sti.nasa.gov

- E-mail your question via the Internet to help@sti.nasa.gov

- Fax your question to the NASA Access Help Desk at (301) 621-0134

- Telephone the NASA Access Help Desk at (301) 621-0390

- Write to: NASA Access Help Desk NASA Center for AeroSpace Information 7121 Standard Drive Hanover, MD 21076 
NASA/TM-1999-209637

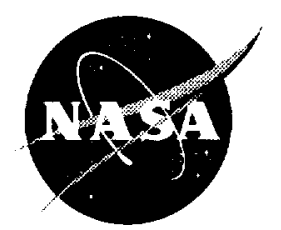

\section{Testing of the Engineering Model Electrical Power Control Unit for the Fluids and Combustion Facility}

Greg L. Kimnach and Ramon C. Lebron

Glenn Research Center, Cleveland, Ohio

David A. Fox

Hamilton Sundstrand Aerospace, Rockford, Illinois

Prepared for the

34th Intersociety Energy Conversion Engineering Conference sponsored by the Society of Automotive Engineers

Vancouver, British Columbia, Canada, August 2-6, 1997

National Aeronautics and

Space Administration

Glenn Research Center 
This report contains preliminary findings, subject to revision as analysis proceeds.

Trade names or manufacturers' names are used in this report for identification only. This usage does not constitute an official endorsement, either expressed or implied, by the National Aeronautics and Space Administration.

Available from

NASA Center for Aerospace Information 7121 Standard Drive

Hanover, MD 21076

Price Code: A03
National Technical Information Service 5285 Port Royal Road Springfield, VA 22100

Price Code: A03 


\section{Testing of the Engineering Model Electrical Power Control Unit for the Fluids and Combustion Facility}

\author{
Greg L. Kimnach and Ramon C. Lebron \\ NASA Glenn Research Center \\ Electrical systems Development Branch \\ 21000 Brookpark Rd. MS. 301-5 \\ Cleveland, $\mathrm{OH} 44135$ \\ (W) 216-433-6251 and 433-6482 \\ (Fax) 216-433-2143 and 433-8410
}

\author{
David A. Fox \\ Hamilton Sundstrand Aerospace \\ 4747 Harrison Ave. \\ PO Box 7002 \\ Rockford, IL 61125-7002 \\ (W) 815-394-3809 \\ (Fax) 815-226-2601
}

\begin{abstract}
The John H. Glenn Research Center at Lewis Field (GRC) in Cleveland, $\mathrm{OH}$ and the Sundstrand Corporation in Rockford, IL have designed and developed an Engineering Model (EM) Electrical Power Control Unit (EPCU) for the Fluids Combustion Facility (FCF) experiments to be flown on the intermational Space Station (ISS). The EPCU will be used as the power interface to the ISS power distribution system for the FCF's space experiments' test and telemetry hardware. Furthermore, it is proposed to be the common power interface for all experiments.
\end{abstract}

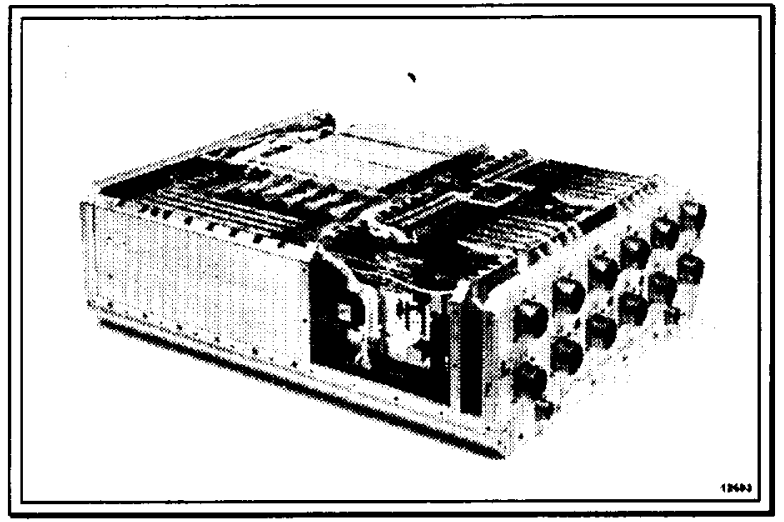

EM EPCU with Cover Removed

Photograph 1

The EPCU is a three kilowatt 120Vdc-to-28Vdc converter utilizing three independent Power Converter Units (PCUs), each rated at 1kWe (36Adc @ 28Vdc) which are paralleled and synchronized. Each converter may be fed from one of two ISS power channels. The $28 \mathrm{Vdc}$ loads are connected to the EPCU output via 48 solid-state and current-limiting switches, rated at $4 A d c$ each. These switches may be paralleled to supply any given load up to the 108Adc normal operational limit of the paralleled converters. The EPCU was designed in this manner to maximize allocated-power utilization, to shed loads autonomously, to provide fault tolerance, and to provide a flexible power converter and control module to meet various ISS load demands.

Tests of the EPCU in the Power Systems Facility testbed at GRC reveal that the overall converted-power efficiency is approximately $89 \%$--with a nominal-input voltage of $120 \mathrm{Vdc}$ and a total load in the range of $40 \%$ to
$110 \%$ rated $28 \mathrm{Vdc}$ load. (The PCUs alone have an efficiency of approximately $94.5 \%$.) Furthermore, the EM unit passed all flight-qualification level (and beyond) vibration tests, passed ISS EMI (conducted, radiated, and susceptibility) requirements, successfully operated for extended periods in a thermal/vacuum chamber, was integrated with a proto-flight experiment, and passed all stability and functional requirements.

Due to paper length limitations, this Technical Memorandum only overviews EPCU operation and tests; a more detailed test report is available [1], as is a Technical Memorandum explaining operational details [2].

\section{INTRODUCTION \& OPERATIONAL OVERVIEW}

The EPCU is an ISS power interface, which converts $120 \mathrm{Vdc}$ to $28 \mathrm{Vdc}$, and was designed for the FCF experiments. The rated, converted power is $3 \mathrm{kWe} @$ $28 \mathrm{Vdc}$ and is available via 48 4Adc output-channels (4 channels per connector) on the front of the unit. Furthermore, the EPCU provides an additional $2.9 \mathrm{kWe}$ of unprocessed-but protected-power at $120 \mathrm{Vdc}$. These 120Vdc feed-throughs are contained in groups of three per connector (two connectors) on the back of the EPCU. The EPCU's feed-through power is not processed: these load connectors are fed by $D C$-to-DC Converter Units (DDCUs) and are subject to DDCU power quality.

Power protection is accomplished with current limiting, solid-state switches which trip according to a $v^{2} t$ timing. (The switch FET voltage is controlled to achieve the current-limiting value of 4Adc: as the load current increases, the voltage drop across the FET increases. The hybrid trips more quickly as the connected load increases beyond the current-limiting value.) These solid-state switches, along with the control and monitoring hardware, are called Remote Power Controllers (RPCs) and have been packaged into a hybrid module. These hybrid switches, which can operate at voltage levels from $18 \mathrm{Vdc}$ to $150 \mathrm{Vdc}$, are the keys to the flexibility and re-configurability of the EPCU.

Because the RPC channels can operate individually or be paralleled in groups of two, three, or four RPCs (i.e., channel capacities of $4 \mathrm{Adc}, 8 \mathrm{Adc}, 12 \mathrm{Adc}$, or $16 \mathrm{Adc}$ ), the EPCU can readily feed any variety of user loads 
requiring $28 \mathrm{Vdc}$ simply by swapping-out external loads' harnesses, which are connected at the front of the EPCU (see Photograph 1). By selecting a harness, which parallels the required number of channels, the EPCU eliminates the need for "experiment-specific" power interfaces. (The harnesses contain programming pins, which cause paralleled channels to operate as if they were one.)

One of the most significant design features of the EPCU is its autonomous power-limiting design, which efficiently utilizes ISS power, and ensures that the EPCU autonomously limits the connected power drawn from the ISS power system. This is accomplished with Dynamic Power Sharing (DPS) and Prioritized Load Shedding (PLS).

The EPCU has two 120Vdc input feeds which may be connected to either of two independent ISS power channels, and each of the three $1 \mathrm{kWe}$ PCUs within the EPCU can be connected to either input feed with a 3PDT relay. The maximum power allocation for each ISS power channel is downloaded to the EPCU via its MIL-STD-1553B interface. (The power allocation needs to be sent only once per the load demand schedule period and does not require that a higher level controller monitor the EPCU.) During normal operation, the EPCU output-paralleled PCUs (inputs are not paralleled!) share output-power equally: as a result, the ISS power feeds proportionally supply the load demand.

This proportional sharing of load, via the DPS controls, continues with increasing load demand until one of the ISS feeds reaches its allocation limit. If the load continues to increase, the PCU(s) connected to the other feed pick up the excess load. This adjustment continues until that feed reaches its allocation limit, at which point the PLS controller begins to shed loads in a prioritized fashion (there are 16 user-selectable levels of priority). Load shedding continues until the busses are again within the allocation limits.

It should be noted that the DPS and PLS functions play a more pivotal role during abnormal operation of the ISS power system. These functions allow the EPCU to continue to feed as much load (i.e., high priority level) as possible in the event that a DDCU feed is lost, severe DDCU voltage droop occurs, other ISS load demand perturbations occur, an EPCU converter fails, or other events which limit the total load capability of the EPCU.

Finally, the EM unit dimensions are approximately $17.5^{\prime \prime} \mathrm{W} \times 21.8^{\prime \prime} \mathrm{D} \times 6.6^{\prime \prime} \mathrm{H}$, and has a mass of approximately $108 \mathrm{lbsm}$. The chassis is a milled aluminum base-plate with aluminum, vertical milledguides. The three PCUs are mounted directly on the base-plate; whereas all other assemblies (for example, $1553 \mathrm{~B}$ card) are wedge-locked into place in the guides.

\section{INITIAL FUNCTIONAL TESTS}

Prior to performing any higher level tests, basic functional checkouts were performed. These tests included functional verification of the MIL-STD-1553B interface, RPC isolation and voltage drop characterization, $120 \mathrm{Vdc}$ feeder isolation verification, and programming pin and initial position tests.

\section{MIL-STD-1553B INTERFACE CHECKOUT}

The 1553B interface was checked to verify that the unit received and implemented basic commands (e.g., bus relay transfer and $\mathrm{PCU}$ on/off) and returned proper status information to the software control interface. Accuracy of the sensors and AV conversion has not yet been quantified.

\section{ISOLATION TESTS}

Isolation tests were done on the $120 \mathrm{Vdc}$ input channels and on the RPCs (120Vdc and 28Vdc). The input channel isolation tests were done to verify that the ISS input feeds would never be shorted together (it is an ISS requirement that channels never be cross-tied, and this is guaranteed by the break-before-make 3PDT relays) and that the two ISS "hot" and "return" lines were isolated from the EPCU chassis. These are, in fact, the results of the tests.

Isolation of $28 \mathrm{Vdc}$ loads connected to the output RPCs (called "A5"s) and $120 \mathrm{Vdc}$ loads connected to $120 \mathrm{VdC}$ feed-through RPCs (called "A12"s) were quantified. This was done by turning "off" the A5 and A12 RPCs, applying $120 \mathrm{Vdc}$ to the EPCU inputs, turning "on" the converters to energize the Point of Regulation (POR) at $28 \mathrm{Vdc}$, and by measuring the output voltage and current of each RPC. The multi-meter provided the short-circuit load for leakage current measurements. Typical A5 leakage was $0.15 \mathrm{Vdc} @ 14 \mu \mathrm{Adc}$, and A12 leakage was 2.8Vdc@60uAdc.

\section{RPC VOLTAGE DROP TESTS}

The test setup had one PCU connected to one power supply ("bus A") and two PCUs to another ("bus B"). Bus $A$ was energized at $120 \mathrm{Vdc}$, and bus $B$ was not energized. The voltage drop across the $28 \mathrm{Vdc}$ and $120 \mathrm{Vdc}$ RPCs were determined. The A5 channel drop was measured by measuring the POR voltage and the load voltage at half load (2Adc) and full load (4Adc). The difference yields the channel drop. The channel drop was also measured directly and compared with the difference between the POR and load voltage values. Furthermore, because there are $484 \mathrm{Adc}$ channels and all hybrids were of the same batch, it was decided to only check four $28 \mathrm{Vdc}$ channels. The results for the $28 \mathrm{Vdc}$ tests are given in Table 1.

The channel-voltage drop at 2Adc is approximately $0.19 \mathrm{Vdc}$, which is an $0.4 \mathrm{We}$ loss. At 4Adc the drop is approximately $0.4 \mathrm{Vdc}$, which is a $1.7 \mathrm{We}$ loss. These losses correspond to $0.7 \%$ and $1.5 \%$, respectively, on a per-channel basis.

Similarly, the $120 \mathrm{~V}_{\mathrm{dc}}$ hybrids were tested, and at $2 \mathrm{Adc}$ load the drop across the channel is approximately $0.14 \mathrm{Vdc}$. At $4 \mathrm{Adc}$ the drop is approximately $0.4 \mathrm{Vdc}$. These values, other than the J3,3 RPC, are consistent with the $28 \mathrm{Vdc}$ RPCs (they are the same hybrids, after 
all). However, because the voltage drop across the FET is current dependent, the percentage losses at the higher input values are $0.12 \%$ and $0.34 \%$, respectively.

\begin{tabular}{|c|c|c|c|c|}
\hline $\begin{array}{l}\text { Bus AM] } \\
\text { Bus B N }\end{array}$ & $\begin{array}{c}0 \\
120.2\end{array}$ & & & \\
\hline FRPC $[\mathrm{Jx}, \mathrm{n}]$ or $[\mathrm{m}]$ & $\mathrm{J} 22,1$ & $\mathrm{~J} 22,2$ & $\mathrm{~J} 22,3$ & $\mathrm{~J} 22,4$ \\
\hline Load Current [A] & 2.106 & 2.105 & 2.095 & 2.102 \\
\hline Vsense (POR) $\mathrm{V}$ ) & 28.771 & 28.769 & 28.773 & 28.771 \\
\hline FRPC Vout [V] & 28.58 & 28.57 & 28.58 & 28.59 \\
\hline Measured Drop M & 0.192 & 0.198 & 0.19 & 0.185 \\
\hline Calculated Drop M & 0.191 & 0.199 & 0.193 & 0.181 \\
\hline FRPC $[\mathrm{J}, \mathrm{n}]$ or $[\mathrm{m}]$ & $\mathrm{J} 22,1$ & $\mathrm{~J} 22,2$ & $\sqrt{22,3}$ & $J 22,4$ \\
\hline Load Current [A] & 4.141 & 4.139 & 4.139 & 4.138 \\
\hline Vsense (POR) M & 28.77 & 28.769 & 28.769 & 28.769 \\
\hline FRPC Vout [V & 28.35 & 28.33 & 28.36 & 28.4 \\
\hline Measured Drop M & 0.42 & 0.436 & 0.408 & 0.371 \\
\hline Calculated Drop [V] & 0.42 & 0.439 & 0.409 & 0.369 \\
\hline
\end{tabular}

28Vdc Hybrid RPC voltage Drops

Table 1

\section{PROGRAMMING PINS \& INITIAL POSITION}

The control software developed for the EM EPCU, in conjunction with the "parallelable" loads of the HyberLoad load bank, afforded testing of the EPCU Initial Position (IP) and parallelability of EPCU $28 \mathrm{Vdc}$ channels. $120 \mathrm{Vdc}$ channels were similarly tested, using dip switches on a specially designed test harness.

The control software and HyberLoad combination eliminated the need to construct varying harnesses for different IP and paralleled channel scenarios, because the HyberLoads can "short" the appropriate pins within a harness. In this manner, all channels were verified to implement IP and paralleling properly.

\section{EFFICIENCY of THREE PARALLELED PCUs}

The efficiency of the PCUs were tested individually and with the three units paralleled. The efficiency numbers do not include the losses associated with the input RPC cards; however, the minimal losses associated with approximately 8 inches of \#14 wires connecting the PCU outputs to the POR are included.

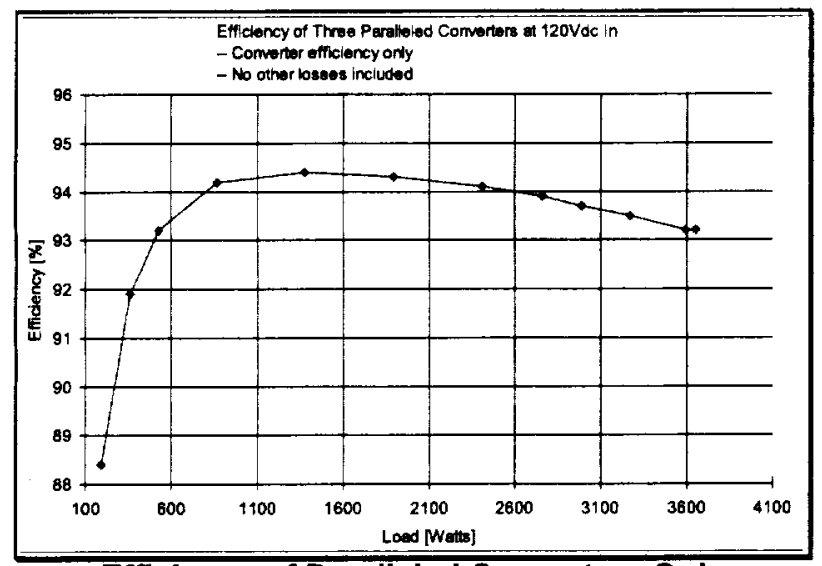

Efficiency of Paralleled Converters Only Figure 1
The efficiency is over $93 \%$ for loads in the range of $500 \mathrm{We}$ to $3000 \mathrm{We}$, and greater than $94 \%$ in the range of $800 \mathrm{We}$ to $2500 \mathrm{We}$. The peak efficiency of the paralleled PCUs is approximately $94.4 \%$. See Figure 1.

\section{EPCU EFFICIENCY TESTS}

The EPCU efficiency tests were run in two different modes of operation:

1. The EPCU having only $28 \mathrm{Vdc}$ loads connected. This mode's efficiency is referred to as the EPCU "converted-power efficiency" and includes all losses (e.g., A5 cards and housekeeping power requirements).

2. The EPCU having $28 \mathrm{Vdc}$ and $120 \mathrm{Vdc}$ loads connected. This efficiency is referred to as the "overall" or "box" efficiency.

The converted-power efficiency tests were run by connecting a $120 \mathrm{Vdc}$ power supply to each EPCU input bus, connecting two converters to Bus $A$, connecting one converter to Bus $B$, and measuring the input current and voltage at the input connectors; furthermore, a special harness was used to measure the total $28 \mathrm{Vdc}$ load current and the voltage at the output of one of the load RPCs (A5 cards). This test configuration results in a very good approximation of the converted-power efficiency, and is shown in Figure 2. The peak, converted-power efficiency is approximately $89.5 \%$.

The design requirement for EPCU efficiency is defined for the overall efficiency, and is greater than $97 \%$ over the "midband" range of loads.

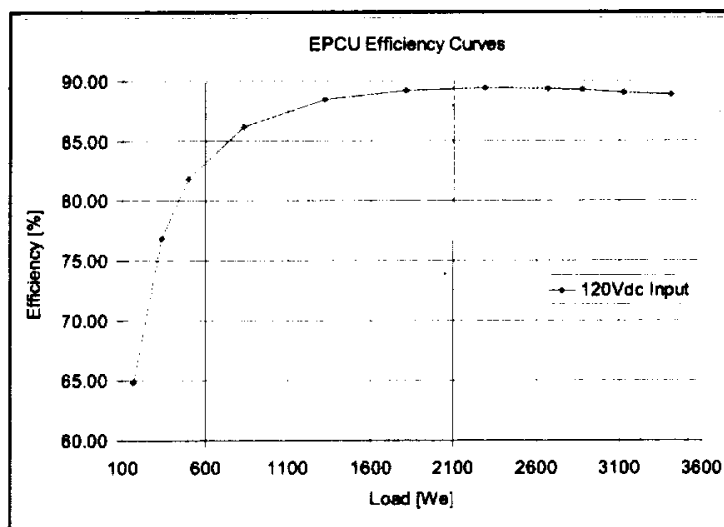

Converted Power Efficiency of EPCU Figure 2

\section{EPCU REGULATION, CURRENT-LIMITING, \& FOLDBACK}

The POR regulation with the three PCUs paralleled and connected to Bus $B$ was tested at input voltages of $116 \mathrm{Vdc}, 120 \mathrm{Vdc}$, and $126 \mathrm{Vdc}$. The load was varied from $0 \%$ to $100 \%$ and it was found that the EPCU regulates the bus to within $0.17 \mathrm{Vdc}$ over the rated load range. 
Voltage foldback occurs because the PWM controller cannot maintain a long enough duty cycle to regulate the POR voltage for a given load and input voltage. Thus, as the load increases, the input-voltage foldback point increases. The voltage foldback point, listed as Vin [ in Table 2, for various load levels was found by decreasing the power supply voltage from $120 \mathrm{Vdc}$ until foldback occurred.

\begin{tabular}{|c|c|c|c|}
\hline Load [A] & Load [We] & Vout M] & Vin [M] \\
\hline 12 & 338 & 27.92 & 101.27 \\
\hline 53.5 & 1500 & 28.04 & 104.71 \\
\hline 107 & 3000 & 27.997 & 106.89 \\
\hline Input Voltage Foldback @ Three Load Levels \\
Table 2
\end{tabular}

\section{SYSTEM \& EPCU STABILITY TESTS}

The EPCU was tested for large and small signal stability, as well as for stand-alone stability. Small Signal Stability (SmSS) is determined using the Nyquist stability criterion and Bode plots. Characterizing the response of the EPCU input and output to load-steps tested Large Signal Stability (LSS). A last measure of stability is the standalone stability, which is a special case of small signal stability.

\section{LARGE SIGNAL STABILITY}

Instead of using a power supply and a Line Impedance Simulation Network (LISN), these tests were performed by connecting the EPCU to the ISS power system testbed located at GRC. A Rocketdyne (RKD) DDCU (rated at $6 \mathrm{kWe}$ ) was connected to a Type III equivalent Remote Power Control Module (RPCM), which fed one input bus of the EPCU via 73 feet of a \#4 power line. Because the RKD DDCU is an EM unit and because the test setup mimics an ISS channel, the response of the system (i.e., EPCU, RPCM and DDCU) to a load step should be more indicative of what would occur on ISS.

LSS testing was accomplished by applying various load steps to the EPCU and monitoring the input and output transient responses. Of primary concern to the ISS EPS is the input response of the EPCU, which must not cause potential instabilities of the secondary power distribution system which lead to, for example, nuisance trips of RPCMs.

The worst-case test was the application of a $3 \mathrm{kWe}$ @28Vdc load-step (i.e., a 0\%-to-100\%) to an unloaded EPCU, having all three converters connected to one bus. The EPCU input-current response (Figure 3) demonstrates a time to first peak, Tp, of approximately $1.2 \mathrm{msec}$., an input-current overshoot of approximately $55.7 \%$ (implies a damping ratio, $\zeta$, of 0.183 ), and a settling time, Ts, of approximately $3.7 \mathrm{msec}$. The input voltage (Figure 3) reaches a minimum of $119.6 \mathrm{Vdc}$ in approximately $900 \mathrm{msec}$ (undershoot is approximately $1.65 \%$ with a $\zeta=0.793$ ), and the voltage $T s$ is undefined because it never exceeds $2 \%$ of its final value: That is, the input bus remains "stiff" in the presence of a large load step placed on the EPCU. Thus, with a worst case load application, the EPCU settles to an input current value of 27Adc within $4 \mathrm{msec}$ of the load step, and-it can be concluded--it will not introduce instability on the input EPS.

Not shown is the EPCU output voltage response to the $0 \%$-to- $100 \%$ load step in which Vout reaches a minimum value of approximately $25.6 \mathrm{Vdc} 230 \mu \mathrm{sec}$ after the load step, and it recovers to within $2 \%$ of $28 \mathrm{Vdc}$ approximately $800 \mu \mathrm{sec}$ after the load step.

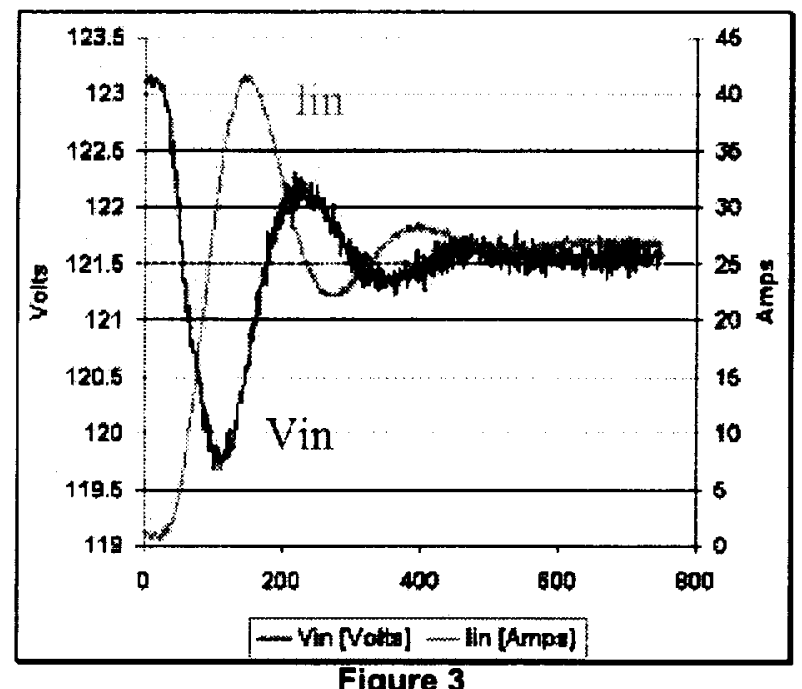

\section{SMALL SIGNAL STABILITY TEST PROCEDURE \&} DEFINITION

SmSS testing was done using the Venable Systems' Impedance Measurement System (IMS). The IMS system injects a swept-frequency small AC signal (either voltage or current), and this small signal excitation and the corresponding response signals are used to determine the impedance of the system under test. For system stability tests, the source impedance (Zsource) seen by the EPCU input includes the DDCU output impedance, the power line, and intermediate switchgear. The load impedance (Zload) is defined as the input impedance of the EPCU.

SmSS of the system is quantified in two ways. First, the Nyquist criterion absolutely ensures stability if and only if the contour of Zsource/Zload does not encircle the $[-1,0]$ point. Alternatively, an ISS requirement for stability imposed upon payloads is that the input impedance of the payload (i.e., the EPCU) falls within the prescribed magnitude and phase limits. The following sections describe the application of these stability requirements to the EPCU.

\section{ISS REQUIRMENTS FOR SMALL SIGNAL STABILITY}

The ISS payload stability requirements (SSP-57000) mandate that the magnitude of the load impedance shall not be lower than that of the source. If, however, the magnitude of the input impedance of the load is lower than that of the source, then the system will be stable if the phase of the load is bounded by the required limits. 
Again, the EPCU was connected to the RKD DDCU and the IMS was used for SmSS testing.

The ISS impedance limit requirements and the small signal impedance of the EPCU, feeding a 107Adc load, are shown in Figure 4a. This Bode plot indicates that for frequencies below $300 \mathrm{~Hz}$, the magnitude of the EPCU input impedance is below the required limit. However, because its phase is within the required limits for frequencies less than $300 \mathrm{~Hz}$, the ISS requirements are met. Furthermore, the Nyquist plot (Figure 4b) demonstrates that the distribution system is unconditionally stable with the EPCU installed.

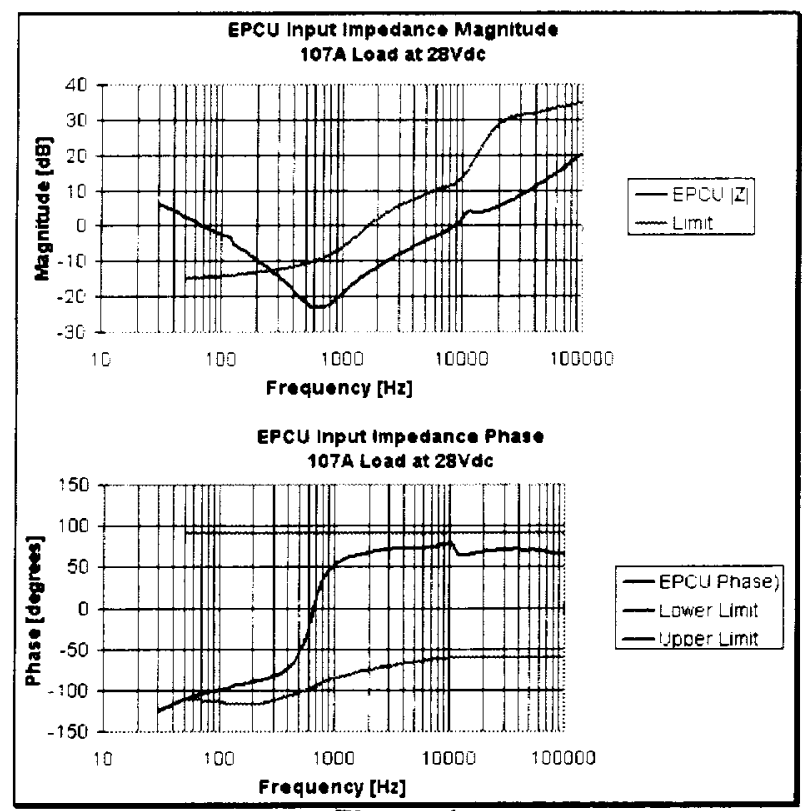

Figure 4a



Figure $4 b$

\section{STAND-ALONE STABILITY}

Stand-alone stability was tested using the IMS with the EPCU connected to the RKD DDCU, as discussed above. The EPCU was tested under the following $28 \mathrm{Vdc}$ loads: 12Adc, 27Adc, 54Adc, 81Adc, and 105Adc. Opening the voltage feedback control loop of the EPCU, injecting a swept-frequency small signal $A C$ stimulus into the voltage-control feedback loop, and then measuring the EPCU output response determines the stand-alone stability for each load condition. The loop gain (i.e., EPCU output response divided by the injected signal) of the EPCU was calculated and displayed by the IMS as both a Nyquist plot and Bode Plot.

The test results for the 105Adc load condition, using Nyquist's criteria and Bode diagrams, indicate that the EPCU is unconditionally stable, and that the EPCU has a stand-alone "gain margin" (i.e., impedance magnitude) of $15[\mathrm{~dB} \Omega$ ] and a minimum phase margin of 84 [degrees]. The results for all aforementioned load conditions indicate that the EPCU should not cause the ISS power system to oscillate or become unstable.

\section{LOAD SHARING}

The EPCU is designed so that the active PCUs share load demand equally (i.e., $33 \%$ each, if three PCUs are active; $50 \%$ each, if two PCUs are active; $100 \%$ if only one PCU is active). This equal power share at the converter outputs results in unequal sharing of power by the $120 \mathrm{Vdc}$ input busses, if an unequal number of converters are connected to the input busses.

Consider the response of the EPCU to a slowly increasing load with two PCUs on one bus and the other PCU on the other bus: As the load demand increases, unequal sharing at the input continues until an allocation limit is reached; further increases in load are then met by drawing the required power from the bus still operating within its allocation limit. When both allocation limits are equaled, further increases in load will result in prioritized load shedding.

One dynamic response test of the load share control circuit was done by loading the EPCU to $1 \mathrm{kWe}$, connecting one $\mathrm{PCU}$ to Bus $\mathrm{A}$, and connecting two PCUs to Bus B. Bus $A$ allocation was set to $460 \mathrm{We}$ and bus $B$ to $8190 \mathrm{We}$. A $28 \mathrm{Vdc}$-load step of $1 \mathrm{kWe}$ was then applied and the response was captured with an oscilloscope. The scope traces are shown in Figure 5. (The scope was set in AC-coupled mode at $100 \mathrm{mV} / \mathrm{div}$ to measure the bus voltage, and the scope was DCcoupled and set at $2.5 \mathrm{~A} /$ div to measure each bus current.) 


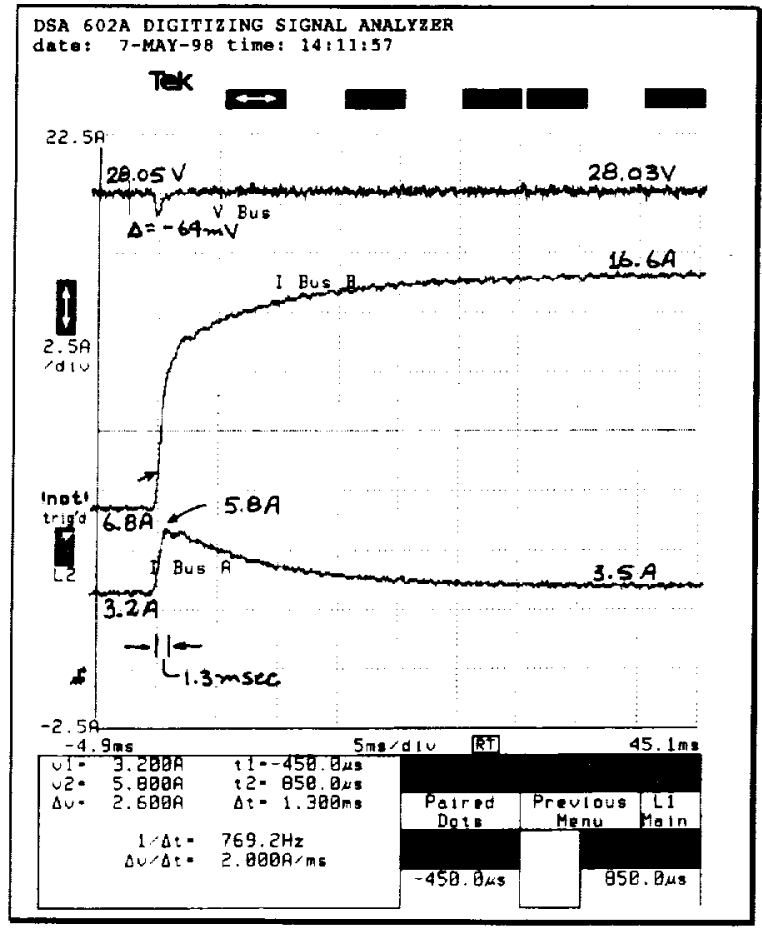

Figure 5

As can be seen in the traces, the busses share power in an approximately 2-to-1 fashion (i.e., 3.2Adc and $6.8 \mathrm{Adc}$ ) prior to the allocation change. The introduction of the load step causes each bus to attempt to proportionally share the additional demand (i.e., the slope of the current response for Bus $B$ is twice that of Bus A). However, because the allocation of Bus A is $460 W e$, the DPS controller begins to limit the current after $1.3 \mathrm{msec}$. The peak Bus $A$ current is $5.8 \mathrm{Adc}$. In steady state, Bus $A$ is limited to $418 \mathrm{We}$ and Bus $B$ picks up the remainder of the load. Also, note that the POR has an $-64 \mathrm{mV}$ transient lasting approximately $500 \mu \mathrm{sec}$.

\section{RPC TRIP CHARACTERIZATION}

The hybrids used on both the 120Vdc RPC cards (i.e., A12 and A13) and 28Vdc RPC cards (i.e., A5) are the same. The trip time of the hybrid is a $v^{2} t$ relationship: that is, the higher the voltage drop across the hybrid's FET, the faster (exponentially) the FET is tripped off. A number of test conditions were run for the A5 cards to demonstrate the tripping of the RPC.

Characterization of the RPC trip curve was accomplished by turning the hybrid on into a short with varying input voltages. Because the FET voltage drop is typically $0.2 \mathrm{Vdc}$ under normally operating conditions, the FET voltage drop progressively increases beyond this value as the hybrid goes "deeper" into current limit. Thus, by connecting a power supply directly to the input of the hybrid and turning the hybrid on into a shortcircuit, the power supply voltage is equal to the FET voltage--thereby simulating various overload conditions. The trip curve is shown in Figure 6.

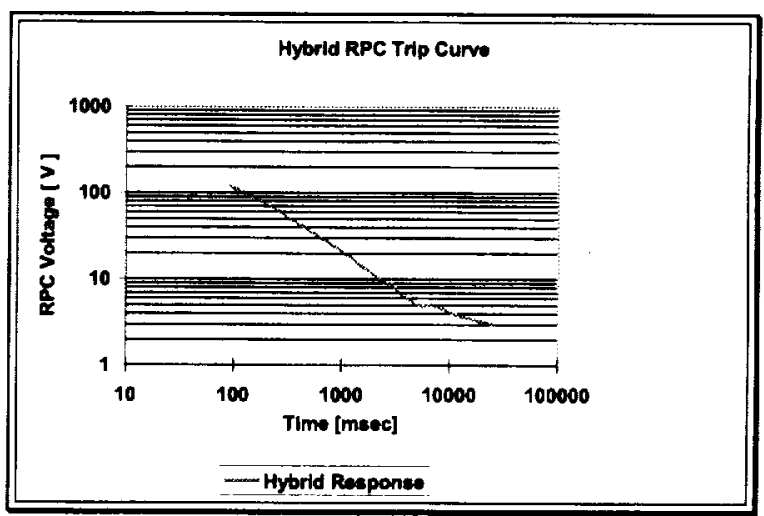

Figure 6

\section{PRIORITIZED LOAD SHEDDING}

PLS is an automatic means of ensuring that the most critical loads remain serviced, in the event that the DPS function cannot redistribute the load between the two input busses such that the feeds remain within their respective allocation limits. The load-shed control is a slower loop than the load share loop, which ensures that re-allocation of load (i.e., the DPS function) occurs first.

There are 16 levels of priority, including a "never shed" priority. PLS was tested under a variety of initial conditions (including one converter just entering currentlimit mode) and with various transients (e.g., loss of an input bus).

Consider the PLS test for which the priority level of 16 4Adc channels was set at 16 successive levels, and the allocation of the busses was adjusted such that the total load on each was just equaled. (One PCU was connected to one bus and two PCUs to the other). A bulk load was then turned on. The total output current was measured by using a specially designed testharness and the oscilloscope was set to trigger on the falling edge of the output current. Because the DPS controls could not redistribute the load without exceeding both bus allocations, loads were shed. Figure 7 is an oscilloscope-captured output-current transient response of the load shedding function. (Because of insufficient bulk load, the response indicates only 13 load-shed steps.) Notice that the load shedding of 13 load levels occurred within $1 \mathrm{sec}$ and that the POR voltage does not show any significant transient. 


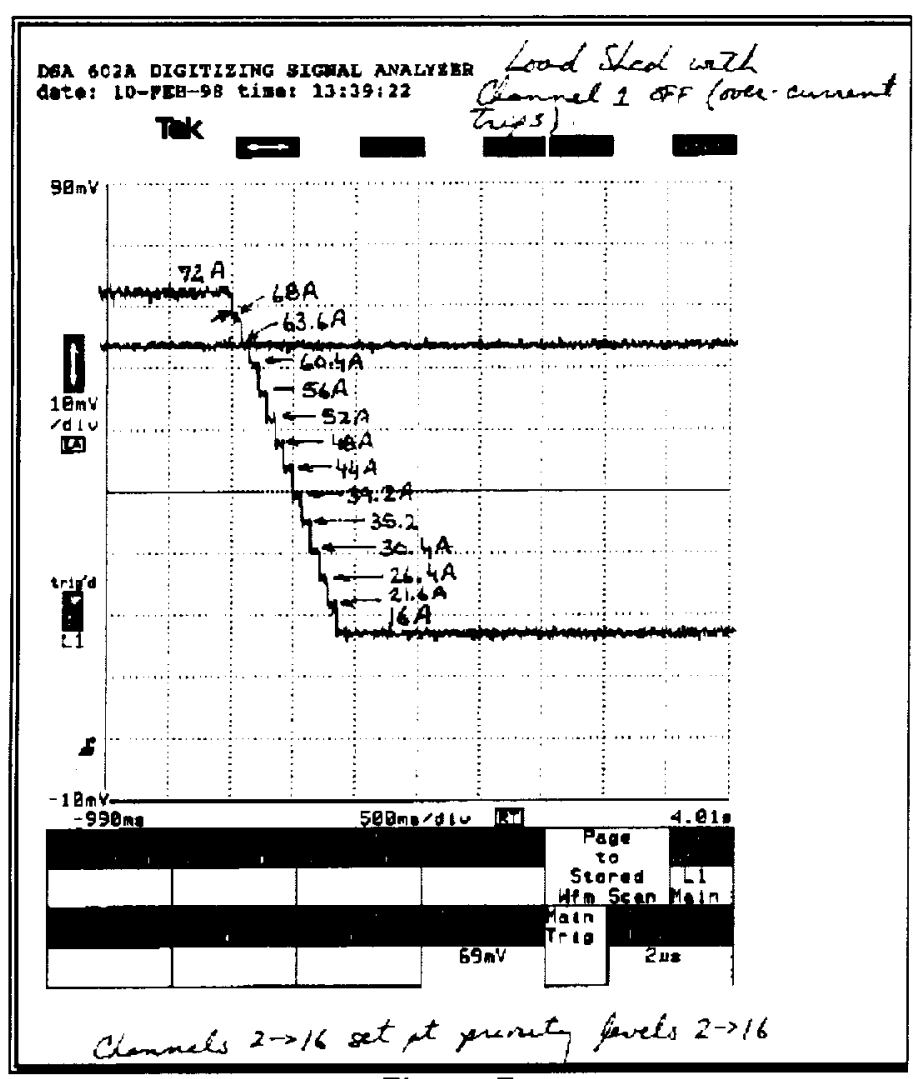

Figure 7

\section{THERMAL-VACUUM TEST}

Although the EPCU will be used in a pressurized module, it was tested in a thermal-vacuum chamber. (The rationale being that an experiment may be required to continue in the event that depressurization occurs and may not be sensed quickly enough to command off the EPCU.) A total of 44 thermocouples were mounted on and within the EPCU at points deemed critical to EPCU operation.

The EPCU will be connected to the ISS Thermal Management System (TMS) via two "quick disconnects" on the back of the unit. Coolant flows through a serpentine path within the base-plate of the EPCU. (The Space Station thermal system coolant specifications are 40[lbs./Hr] @65F and 200[lbs./Hr] @ 115F.)

Thirty-two thermal data points were electronically collected by a Molytec data acquisition system and sent to a PC; the remaining 12 channels were collected with an external data acquisition system and also sent to the PC. Three of the data points are external temperature measurements-most notably the faceplate temperature, which is important because the "touch temperature" is required to be below 114F.

Initial testing of the EPCU was done in open-air conditions at various load levels (i.e., $50 \%$ and $100 \%$ rated load levels) to obtain a baseline of performance. Furthermore, these baseline tests were performed with maximum cooling to establish the baseline data with low risk to the unit. The tests were then repeated in vacuum and the thermal rejection and operating temperatures were measured.

The thermal-vacuum tests highlighted a number of problems, which were corrected. These included the PCB-to-card guide and the RPC-to-PCB interfaces, which resulted in operating temperatures (in vacuum) higher than acceptable. These interfaces were corrected with the application of Cotherm, and the RPChybrid operating temperatures have been reduced by $30 \mathrm{~F}$-back to within acceptable levels.

\section{ELECTRO-MAGNETIC INTERFERENCE TESTS}

The Engineering Model (EM) EPCU was tested according to the International Space Station (ISS) Electromagnetic Emissions and Susceptibility Requirements (documents SSP 30237 rev $C$ and SSP30238 rev C). The tests were conducted in the NASA GRC's EMI Laboratory. These tests involved conducted emissions tests on the EPCU input and output power terminals, conducted power line DC transients, conducted susceptibility, radiated emissions, and radiated susceptibility.

Additional tests were run from the ISS Pressurized Payloads Interface Requirements Document (SSP 57000). These additional tests involved EPCU output voltage ripple frequency spectrum, time domain input voltage ripple measurements, large signal stability tests, and common mode voltage and current susceptibility tests.

The unit passed most EMI tests necessary for ISS flight qualification. Those it did not pass were either corrected or shall have waivers sought. EMI test procedures and test results are fully documented in the Fluids and Combustion Facility EPCU EM EMI Test Report.

\section{VIBRATION TESTS}

The EM EPCU was not originally intended to undergo vibration tests, because many of its integrated circuit and electronic components are mounted in sockets. However, the Electrical Systems Development Branch decided to run vibration tests with the EM unit to verify the structural design of the unit, and to identify major structural problems that would require a major redesign of the EPCU. The vibration tests were run in NASA GRC's Structural Dynamics Lab. Vibration tests included 2.5 minutes of 20 to $2000 \mathrm{~Hz}$ random vibration on the $x, y$, and $z$ axes at a level of $4.4 \mathrm{~g}$ 's RMS and 7.4 $g$ 's RMS. Also, there was a sine burst test of 30 cycles at $20 \mathrm{~Hz}$ along the $x$-axis. This test was intended to simulate impulse acceleration in the direction of the flight. The levels for this sine burst test were $7 \mathrm{~g}$ 's RMS and $14.8 \mathrm{~g}$ 's RMS for 1.5 seconds. Sine wave characterization sweep tests from 20 to $500 \mathrm{~Hz}$ (2 octave/minute) at $0.25 \mathrm{~g}$ 's were run before and after each vibration test in order to detect any abnormal resonance that would indicate any damage to the unit during the test. 
In addition, electrical checkout tests were run on the EPCU after each vibration test to make sure that the unit was still fully operational. The EPCU EM passed the qualification level vibration tests required for space shuttle launch and ISS flight. The vibration test profiles and EPCU accelerometers data are fully documented in the Fluids and Combustion Facility EPCU EM Vibration Test Report.

\section{CONCLUSIONS}

The Engineering Model Electrical Power Control Unit is a $3 \mathrm{kWe}$ power interface designed to interface $28 \mathrm{Vdc}$ Fluids/Combustion Facility Experiments with the International Space Station's 120Vdc-distribution bus. The EPCU incorporates Dynamic Power Sharing and Prioritized Load Shedding to effectively utilize allocated power and to ensure sustained power for critical loads during abnormal operating conditions.

Initial testing of the EM EPCU was completed in October 1998. The EPCU passed the electrical, thermal, EMI, and thermal/vacuum tests, which identified only a few correctable problems.

\section{REFERENCES}

[1] Test Report: "Fluid Combustion Facility Electrical Power Control Unit Engineering Model: Test and Verification". Kimnach, Greg \& Lebron, Ramon [GRC] and Fox, David [Hamilton Sundstrand Aerospace]. June 1998.

[2] NASA Technical Memorandum: "Design and Testing of a Breadboard Electrical Power Control Unit for the Fluid Combustion Facility Experiment". Kimnach, Greg \& Lebron, Ramon [GRC] and Fox, David [Hamilton Sundstrand Aerospace]. 1997.

\section{CONTACT INFORMATION}

Greg Kimnach, NASA Glenn RC at Lewis Field. 216 433-6251. 21000 Brookpark Rd./MS 301-5, Cleveland, OH. 44135 .

Ramon C Lebron-Velilla, NASA Glenn RC at Lewis Field. 216-433-6482. 21000 Brookpark Rd./MS 333-2, Cleveland, OH. 44135.

James V. Soltis, NASA Glen RC at Lewis Field. 216433-5444. 21000 Brookpark Rd./MS 301-5, Cleveland, OH. 44135. 

Public reporting burden for this collection of information is estımated to average 1 hour per response, including the time for reviewing instructions, searching existing data sources. gathering and maintaining the data needed, and completing and reviewing the collection of intormation. Send comments regarding this burden estimate or any other aspect of this collection of information. including suggestions for reducing this burden, to Washington Headcuarters Services. Direciorate for Intormation Operations and Zeports. 1215 Jefferson Davis Highway. Suite 1204. Arlington. VA 22202-4302, and to the Ottice of Management and Budget. Paperwork Reduction Project (0704-018B). Washington, DC 20503.

\begin{tabular}{l|l|l|} 
1. AGENCY USE ONLY (Leave blank) & 2. REPORT DATE & 3. REPORT TYPE AND DATES COVERED
\end{tabular}

\begin{tabular}{|l|l|l}
\hline & December 1999 & Technical Memorandum \\
\hline
\end{tabular}

\section{TITLE AND SUBTITLE}

5. FUNDING NUMBERS

Testing of the Engineering Model Electrical Power Control Unit for the Fluids and Combustion Facility

\section{AUTHOR(S)}

Greg L. Kimnach. Ramon C. Lebron, and David A. Fox

\section{PERFORMING ORGANIZATION NAME(S) AND ADDRESS(ES)}

National Aeronautics and Space Administration

John H. Glenn Research Center at Lewis Field

Cleveland. Ohio 44135-3191

WU $-398-20-0 \mathrm{C}-00$

\section{SPONSORING/MONITORING AGENCY NAME(S) AND ADDRESS(ES)}

National Aeronautics and Space Administration

Washington. DC 20546-0001

8. PERFORMING ORGANIZATION REPORT NUMBER

E-11967

10. SPONSORING/MONITORING AGENCY REPORT NUMBER

NASA TM-1999-2096.37

\section{SUPPLEMENTARY NOTES}

Prepared for the 34th Intersociety Energy Conversion Engineering Conference sponsored by the Society of Automotive Engineers, Vancouver, British Columbia. Canada. August 2-6. 1997. Greg L. Kimnach and Ramon C. Lebron, NASA Glenn Research Center: David A. Fox. Hamilton Sundstrand Aerospace, P.O. Box 7002, Rockford, Illinois 61125-7002. Responsible person. Greg L. Kimnach, organization code 5450, (216) 43.3-6251.

12a. DISTRIBUTION/AVAILABILITY STATEMENT

12b. DISTRIBUTION CODE

Unclassified - Unlimited

Subject Category: 20

Distribution: Nonstandard

This publication is available from the NASA Center for AeroSpace Information. (301) 621-0390.

13. ABSTAACT (Maximum 200 words)

The Johm H. Glem Research Center at Lewis Field (GRC) in Cleveland. OH and the Sundstrand Corporation in Rockford. IL have designed and developed an Engineering Model (EM) Electrical Power Control Unit (EPCU) for the Fluids Combustion Facilin (FCF) experiments to be flown on the International Space Station (ISS). The EPCU will be used as the power interface to the ISS power distribution system for the FCF's space experiments" test and telemetry hardware. Furthermore. it is proposed to be the common power interface for all experiments. The EPCU is a three kilowatt $120 \mathrm{Vdc}-10-28 \mathrm{Vdc}$ converter utilizing three independent Povier Comerter Units (PCUs), each rated at $1 \mathrm{kWe}$ (36Adc @ 28Vdc) which are paralleled and synchronized. Each converter may be fed from one of two ISS power channels. The $28 \mathrm{Vdc}$ loads are connected to the EPCU output via 48 solid-state and current-limiting switches, rated at 4 Adc each. These switches may be paralleled to supply any given load up to the $108 \mathrm{Adc}$ normal operational limit of the paralleled converters. The EPCU was designed in this manner to maximize allocated-power utilization. to shed loads autonomously. to provide fault tolerance. and to provide a flexible power converter and control module to meet various ISS load demands. Tests of the EPCU in the Power Systems Facility testbed at GRC reveal that the overall converted-power efficiency is approximately $89 \%--w i t h$ a nominal-input voltage of $120 \mathrm{Vdc}$ and a total load in the range of $40 \%$ to $110 \%$ rated $28 \mathrm{Vdc}$ load. (The PCUs alone have an efficiency of approximately $94.5 \%$.) Furthermore. the EM unit passed all flight-qualification level (and beyond) vibration tests. passed ISS EMI (conducted. radiated. and susceptibility) requirements. successfully operated for extended periods in a thermalhacuum chamber. was integrated with a proto-flight experiment. and passed all stability and functional requirements. Due to paper length limitations. this Technical Memorandum only overview's EPCL operation and tests: a more detailed test report is available. as is a Technical Memorandum explaining operational details.

\section{SUBJECT TERMS}

International Space Station; Spacecraft power supplies; Power modules;

Power converters; Power conditioning

\begin{tabular}{|c|c|}
\hline $\begin{array}{c}\text { 17. SECURITY CLASSIFICATION } \\
\text { OF REPORT }\end{array}$ & $\begin{array}{c}\text { 18. SECURITY CLASSIFICATION } \\
\text { OF THIS PAGE } \\
\text { Unclassified }\end{array}$ \\
Unclassified
\end{tabular}

NSN 7540-01-280-5500

\section{SECURITY CLASSIFICATION OF ABSTRACT \\ Unclassified}

\section{NUMBER OF PAGES}

16. PRICE CO 14

\section{LIMITATION OF ABSTRACT}

